\title{
TEMPERED GLASS OBTAINED BY WATER COOLING
}

\section{Taras Zheplynskyi ${ }^{1}$, Oksana Bulych}

1. Department of Chemical Technology of Silicate Material, Lviv Polytechnic National University, UKRAINE, Lviv, Bandera str. 12, E-mail: zheplynskyi@ukr.net, kseniaserkiz@gmail.com

\begin{abstract}
A new energy-saving and efficient method of glass tempering by using water as a cooling agent is described. This glass is not inferior to the strength of traditional tempered glass. In addition, it does not fall to pieces during drilling and cutting and it is characterized by higher chemical resistance and microhardness.
\end{abstract}

Keywords - float glass, tempering, acid resistance, microhardness, stresses, stress diagram, electricity consumption.

In connection with the growth of pace of building and mechanical engineering development nowadays tempered glass has more and more applications. This glass features much greater strength compared to ordinary float glass. In addition, its important advantage is that after breaking it does not form large debris. It falls to small pieces with blunt edges, which can not cause significant injuries to people. This feature is important for window glazing of top floors of multistory buildings, as well as for side and rear windows of cars. For front windows of cars triplex with semitempered glass is applied. This glass has slightly lower strength compared to tempered one, but after breaking it preserves the integrity of the window and allows a driver to get to the repair service.

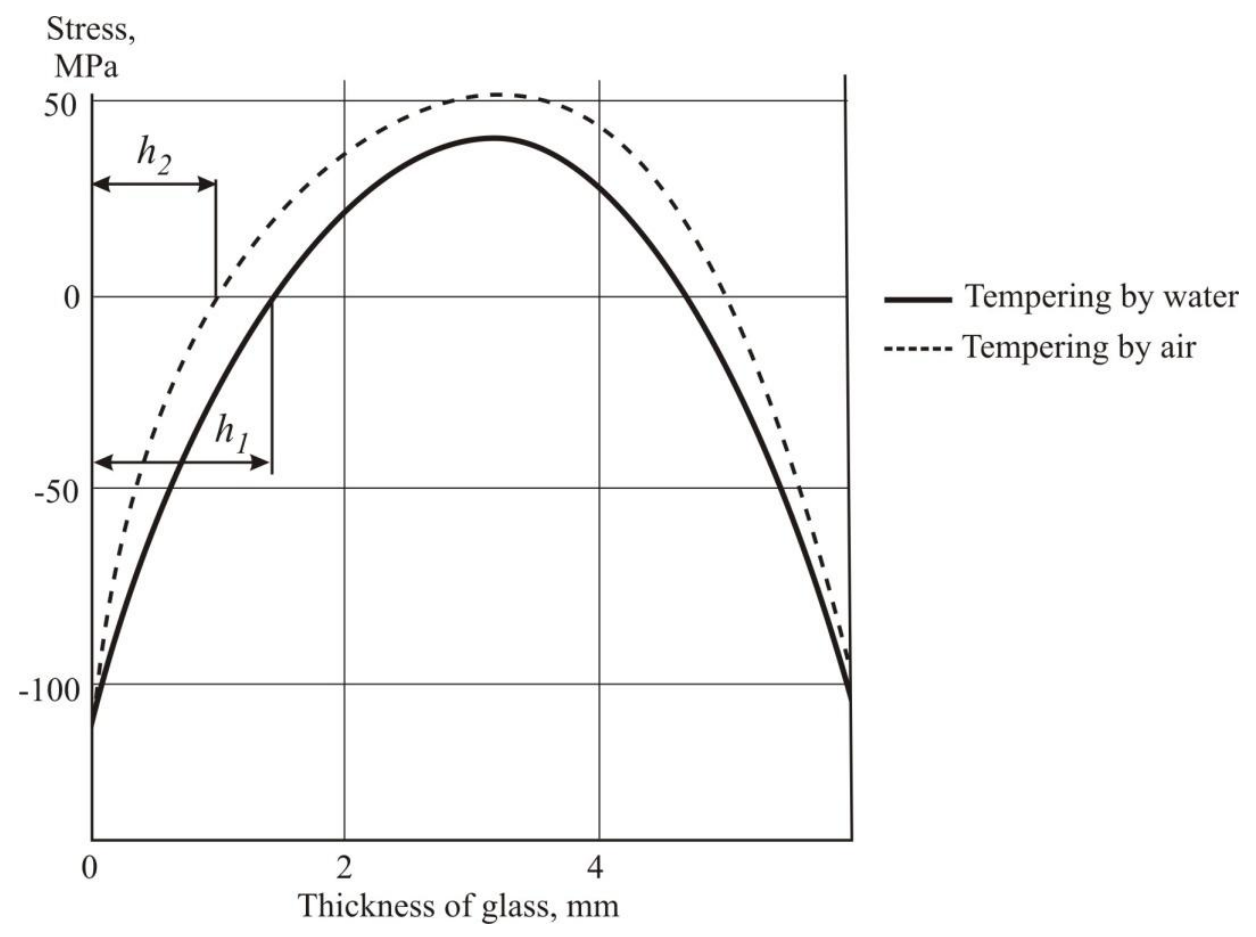

Fig, 1. Diagram of stress distribution in glass tempered by water and air (thickness of compressed layer $\mathrm{h}_{1}=1,4 \mathrm{~mm} \mathrm{~h}_{2}=1 \mathrm{~mm}$ ).

Despite the significant advantages, tempered glass has also a number of drawbacks. The first disadvantage is the high cost and energy intensity of modern method of glass tempering. In order to temper glass, it must be heated to the temperature of $600-700{ }^{\circ} \mathrm{C}$, and then is blown for $10-20$ seconds by ventilators with the power of $600 \mathrm{~kW}$. In order to get semi-tempered glass, which is put into front windows of cars, it is cooled by air heated to $80-400{ }^{\circ} \mathrm{C}$. This makes the glass even more expensive. 
After tempering stresses are formed in the volume of glass, the distribution of which is described by a diagram in the form of parabola. Its edges indicate the amount of compression stresses on the surface, and the placement of peak in the diagram depends on the maximum amount of tensile stresses in the middle layer of glass. The compressive stresses (fig. 1) on the surface are approximately $110 \mathrm{MPa}$, and the tensile stresses in that glass are $50 \mathrm{MPa}$. The permissible value of tensile strength of float glass which is taken at the calculations is $30 \mathrm{MPa}$. Thus, during cutting or drilling, tempered glass will fall to pieces as soon as the cutting tool reaches the zone of location of destructive tensile stresses.

Furthermore, as a result of traditional tempering the microhardness and chemical resistance of glass decreases.

Elimination of all above-mentioned drawbacks can be done by introducing into production our patented method of glass tempering by water cooling $[1,2]$. The method consists in the fact that before heating the glass is fixed between two heat-resistant and heat conductive plates. After that, this complex is heated in a furnace to the tempering temperature, and its cooling is carried out by spraying the plates with ordinary water. The heat conductive plates make it possible to distribute evenly the cooling effect of water throughout the entire surface of heated glass. If heated glass surface is watered without such plates - the glass will break. The reason for this is uneven cooling, which occurs due to the formation of heat-insulated zones in places of water evaporation.

Glass tempered by the proposed method is not inferior to the strength of traditional tempered glass, but is much cheaper. Average electricity consumption of traditional tempering method is about $100 \mathrm{kWh}$, and in the proposed method it is only $10 \mathrm{kWh}$. In addition, the tensile stresses in the middle layer of such glass are approximately $30 \mathrm{MPa}$ (Fig. 1), which means that it can be cut and drilled. The obtained results (fig. 1) make it possible to estimate the thickness of the compressed layer in tempered glass. As a result of water cooling, this thickness rises from $1 \mathrm{~mm}$ to $1.4 \mathrm{~mm}$. This indicates that the introduction of the new glass tempering technology will also increase the operational reliability of glass (scratch resistance).

Another advantage of the proposed method is that it also allows to obtain obsemi-tempered glass by increasing the thickness of heat conductive plates.

Research indicates that the reason of reduction of microhardness and chemical resistance of draditional tempered glass is uneven cooling that occurs during the air blowing of hot glass. In this case, zones of overstresses that cause these deterioration of surface properties are formed. The usage of heat conductive plates at glass cooling with water allows to make it more uniform. As a result, the microhardness of tempered glass rises from $5300 \mathrm{MPa}$ to $5400 \mathrm{MPa}$, while the mass loss after the acid resistance test decreases from $2.5 \mathrm{mg} / \mathrm{dm}^{2}$ to $2.2 \mathrm{mg} / \mathrm{dm}^{2}$.

Therefore, the proposed method of tempering glass not only allows to increase glass strength at the level with the traditional, but also has a number of advantages. This includes lower cost, greater energy efficiency, higher microhardness, chemical resistance and operational reliability.

[1] T. Zheplynskyy, O. Serkiz, "Contact method of glass toughening", Glass International, vol. 36, no. 6, 42-44, 2013.

[2] T. Zheplynskyy, O. Serkiz, M. Golovchuk, M. Ois "Toughening of glass surfaces by air and contact method", Glass International, September, 2015. http://www.glassinternational.com/features/view/toughening-of-glass-surfaces-by-air-and-contact-methods 